\title{
Impacts of Domestic Load and Electric Vehicles on Domestic Consumption in UK
}

\author{
M. A. Sheboniea \\ Brunel University, U.K. \\ mussa.sheboniea@brunel.ac.uk
}

\author{
M.K. Darwish \\ Brunel University, U.K. \\ mohamed.darwish@brunel.ac.uk
}

\author{
Al Janbey \\ LCUCK, U.K. \\ a.janebey@lcuck.ac.uk
}

\begin{abstract}
This paper highlights domestic consumption of electricity in UK and effect of electric vehicles on the domestic demands. Also, consider the trends and growth of domestic electricity demand and the implication of using the electric vehicles. One challenging factor is the management of the domestic load electricity demand on the electric vehicles. To this end, this paper investigates new management technology technique that can be used in domestic sector. The key point to tackle this problem is to outline pattern shape of the electricity usage per individual household. However, lack of information on individual usage per consumer is complicating the path to the new solutions. Data were collected from daily energy consumption and energy peak demands from UK electricity industries. In additional the research explores the effect of recently introduced UK energy plan to reduce the $\mathrm{CO} 2$ emission and how this affects usage of the electric vehicle. The proposal in the new solutions includes the use of renewable energy sources such as solar panels and batteries banks for domestic supply. This would go a long way to reducing electricity demand as well as reduce $\mathrm{CO} 2$ emission from domestic sector.
\end{abstract}

Index Terms-- Domestic consumption, domestic load Electrical Vehicle, PHEV

\section{INTRODUCTION}

It is expected that in the next few years, there would be a remarkable growth for the utilization of electric vehicles. First and foremost it is a new and extremely important trend that has been followed by individuals across the world specifically because it is regards technology [1]. It is an important fact to note that PHEVs will certainly have a significant influence on the overall loads of supplies of domestic electricity loads. Moreover, it can also have a significant increase towards the risk of overloading the power system if new alternates are not implemented for increased demands of energy [2].

One of the most important purposes of such an investigation and analysis is to summarize the significance of electricity demands for the various households in the UK with increased usage of PHEVs which is can affect the overall process [3]. It is a fact that the electrification of transportation sector does offer an opportunity for introducing national as well as international emission intends for energy security as they would reduce dependency towards fossil fuel and would also lower local and international emissions for $\mathrm{CO} 2$ [4]. The infrastructure for UK electricity would be managed in an effective manner for providing large amounts of driving energy for significant portions of domestic electric vehicles across the country. To this reason, the region of UK has been emphasizing on changing its options to charge domestic electric vehicles through the means of national electric grid. They also provide how different solutions can affect future outcome from various perspectives including quality of life, electricity consumption and generation [5]. Considering the use of electrical cars, UK authorities are commitment for power consumption for two reasons. As a matter of fact, comparison is done with power loading in which the usage of electrical vehicle frequently used for household purpose. In addition to it, the carbon dioxide emission is considered as the ecological aspect, which must be reduced for securing environmental sustainability. The distribution of power is highly influenced from electrical vehicle as this is proved to consume more electricity alongside with household's appliances and lighting [6]. In near future, the UK potential market share of PHEV expected to be around 25\% [2]. Fig.1 shows the percentage of market share. The use of cars and vans in UK has roughly tripled in matter of kilometres since 1970 [1]. With introducing the electric vehicles as domestic electricity consumer, there is a need to meet their demand from the national grid [6].

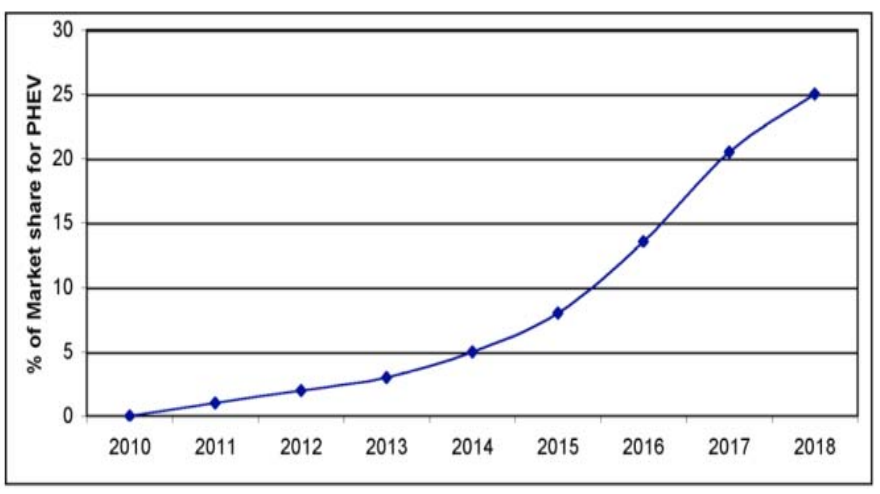

Fig.1. Potential market share of PHEV.

The domestic sector in UK is accountable on almost third of $\mathrm{CO}_{2}$ emissions. Fig.4 shows the yearly amount of $\mathrm{CO}_{2}$ emissions from the transportation sector in million tons. The electricity generation process is increasing at peak demand period which is leading to more and more of $\mathrm{CO}_{2}$ emission due to the increasing of the supply to meet the daily peak demand $[7,8]$. On the same hand the transportation sector also is contributing with reasonable amount of $\mathrm{CO}_{2}$ emission 
and the UK is amongst the countries which are committed to reduce their $\mathrm{CO}_{2}$ emission contribution [1].

Considering the perspective of demand, remitting to charge the operations of power system highly results in responsive load. In practical terms, the consumption of energy through electrical vehicles has increased as these can be easily charged in daily usage. According to the research of electric power research institute, there would be increase of 35 percent by 2020 in PEV's vehicle. Moreover, it is also expected to increase the rate by the year of 2040. In similar manner, 62 percent of overall electric vehicle would increase by 2050. Fig.2. illustrates the ownership pattern of owing cars per household in UK for the period 1980 to 2006. The percentage that more than one car been used in one household have doubled [1].

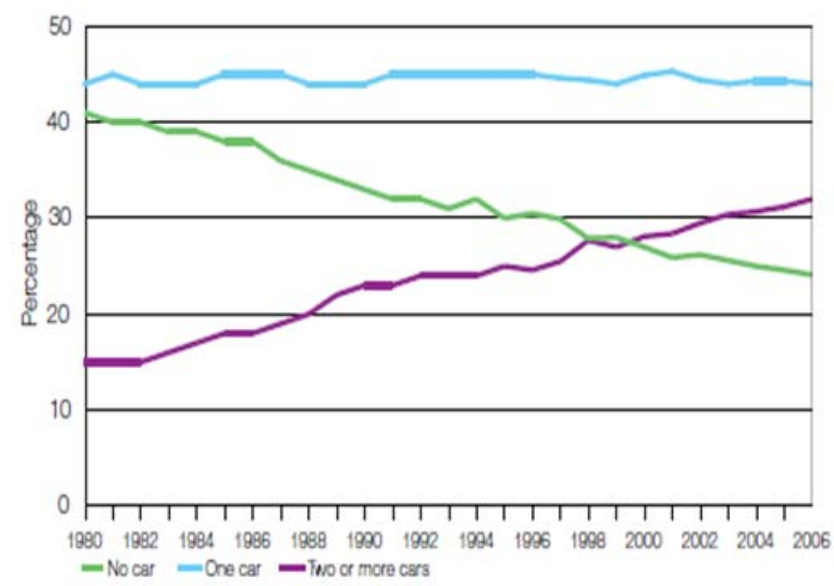

FIG.2. CARS OWNED \% BY HOUSEHOLD GB

\section{DOMESTIC SECTOR AND PHEV}

In the UK, the peak demand of consuming electricity occurs in the period lay between 17-22 hrs. This time the household will be occupied where the people start tripling back home form schools, works and etc. and start preparing the main daily meal and continue till people start getting to rest. In addition to that, in case of electric vehicles is been used the occupier will intend to charge the vehicle's battery immediately once got back to the household. Fig. 3 shows the peak demand period for a typical UK household whereas Fig.4 shows the effect of charging the PHEV on the daily consumption with different PHEV integration to the national grid [6].

Fig. 5 is the description of domestic electricity consumption on the yearly basis. From figure, it is evident that with the rapid progress in the human civilization, fossil fuels and their consumption has increased [9]. In the modern times, it can be said that non-renewable resources have been recognized as will be expired soon and there is a need to be replaced by other forms of energy. In addition, 20 percent of almost $60 \%$ of the transportation (cars) sector expected to be partly or fully domestically charged using the national grid.

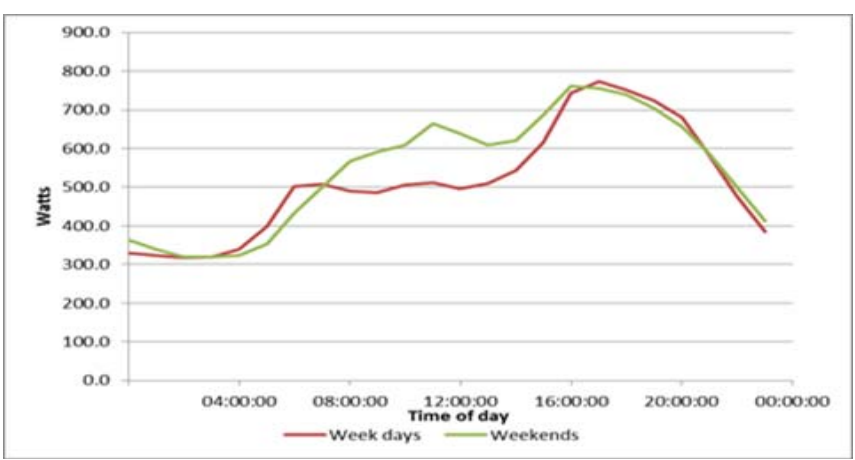

Fig.3. Time of demand of typical household [10]

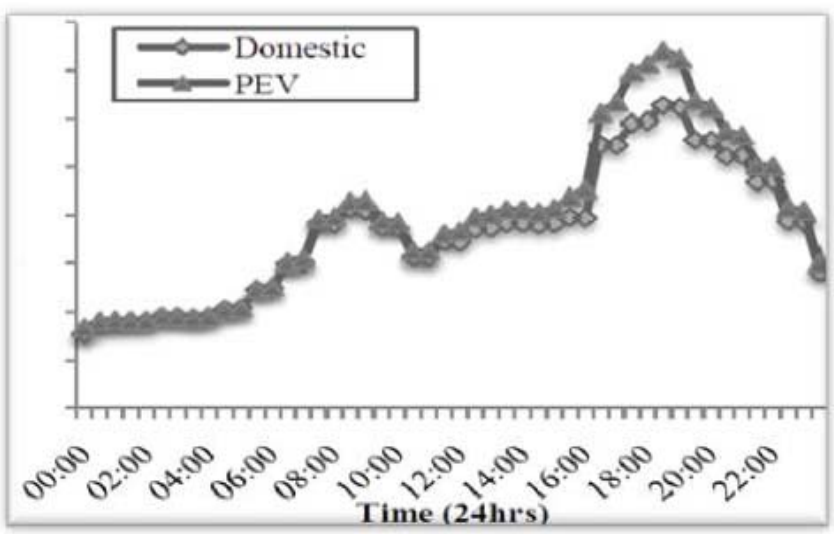

Fig.4. Domestic and PHEV peak consumption period [2]

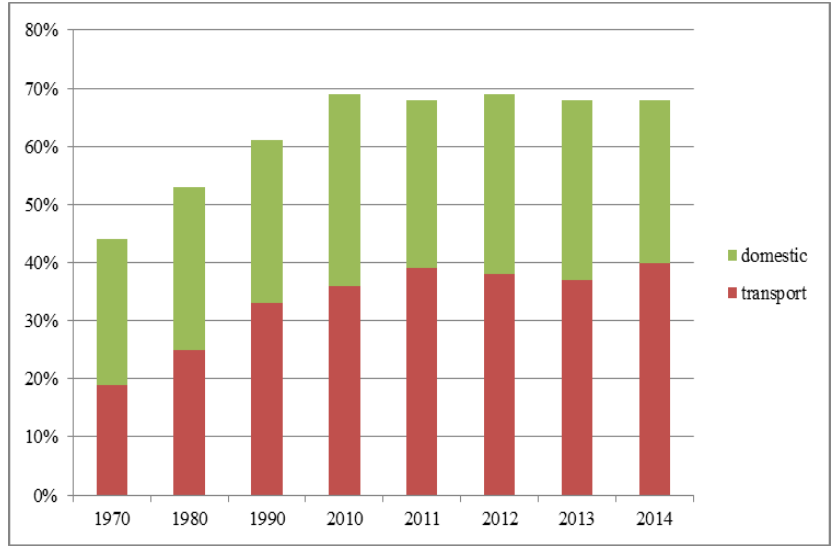

Fig5.domestic and transportation sectors percentage share of UK final consumption [11]

On the other hand, the ecological issues have also been associated. For becoming energy efficient, the developed countries are now considering social, political and ecological aspects as well as technological ones in order to respond to the challenges and commitment. The rolling out of the smart meters is considered as the initiative and model as expected 
this will be backbone of the information technology needed to move towards smart grid [12].

UK government is taking initiatives in the form of smart grid technology which is the amalgamation of the two way communications and flow of information so that the grid can be made more energy efficient with adopting such approaches, which are including time of use and dynamic for decreasing the peak demand with the help of shifting load of demand over higher prices during the peak time which the electric vehicle expected to be connected to the grid [13].

The interactive and intelligent system like the above is developed for helping the consumers to control and understand their energy usage having final goal of lowering the consumption of energy especially during peak demand period. For generating the feedback on raising awareness and consumption, various efforts have been made on developing modern technologies. Smart grid is one of the significant techniques; however, there are many methods that follow automated approach. Smart grid highly centers on management of electricity supply and focuses on using multiagent system and machinery applications [14],[15].

The aim of Smart grid is to provide control on home energy occupancy and off-grid management with respect of using electric vehicles. Nevertheless, the solution focuses on individual's personal approach for dealing grid so it can optimize energy usage by meeting the demands of household. Moreover, highly electricity demand loads and PHEV's battery charging could be shifted in off-peak times that can be found in current tariffs and automation [16].

For instance, few providers offer low rates of electricity, particularly in night hours which highly boost their sales. Furthermore, this offer is particularly designed for those people who have meter installed in their homes [17]. Therefore, the tariffs have different rates of electric supply, different methods that provide opportunities for selecting the desired timing for charging the HPEV. In addition to it, the systems are particularly designed for deregulating the market of electricity which shows that purchasers can select between the choice of tariffs and suppliers. The scheme is developed as per particular standard which can straightly enter into other data sources of tariff which includes equipment metering [18].

\section{HYBRID PLUG IN ELECTRICAL VEHICLE PHEV}

An electric grid solution does have a significant impact on electricity production and also focuses on the emissions that arise from electricity. Results comprise of different regional differences regarding $\mathrm{CO} 2$ emissions and its cost impact. During the day, battery charge can have twice the same impact when it is charged during the night time. If new solutions are imposed by the electricity grid of UK, including renewable and solar energy, results would comprise of a significant decrease towards emissions of $\mathrm{CO} 2$.

Specific questions that could be presented regarding new solutions could be, for instance, what is the impact of potential dissemination regarding plug-in hybrid as well as electric vehicles for production of electricity and what would be their impact on intensity of $\mathrm{CO} 2$ at a regional level? The core emphasis would be towards minimizing operational cost for fulfilling load requirements [2]. According to a data, more than $20 \%$ of carbon emissions that arise from passenger and transportation cars arise at a rate of almost 59.2\%. The government of UK has targeted towards an $80 \%$ reduction in such instances by 2050 .

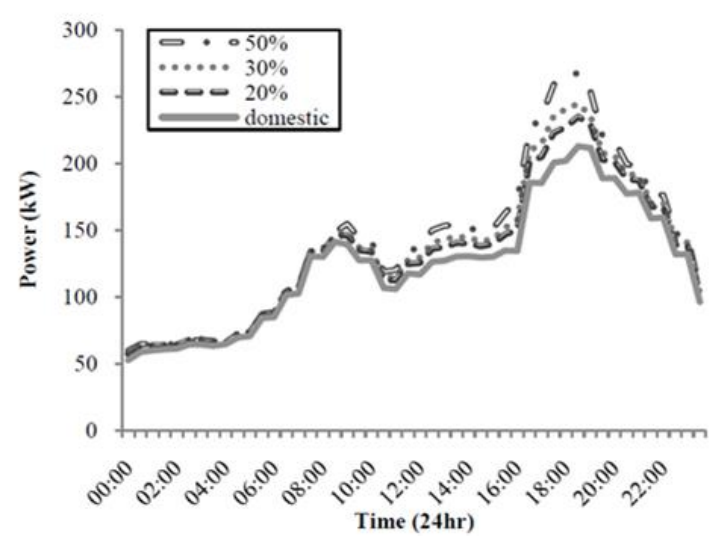

Fig6.domestic demand with varying PHEV integration [2]

Utilization of vehicles that are battery electric as well as plug-in hybrid certainly presents a significant solution from a social, economic, environmental and ecological aspect. Moreover, they can also help to significantly reduce consumption of fuel along with reorder energy for renewable energy sources.

A detailed evaluation of current domestic consumption with the UK along with car use would help towards an understanding for the utilization of PHEV's as well as their impact on the electrical system.

According to a report by National Travel survey (NTS) 2009, there were more than 35 million licensed vehicles that were registered in UK. Moreover, there are almost 30 million cars that are licensed. Moreover, $89 \%$ of them are owned by private users [16].

A rate of charge is constantly used. Moreover, PHEV users would initiate to for charging their cars on an immediate basis when they want to arrive home. Given below is the procedure for calculation of a round trip for driving times. 
Calculating the time of charge with assumption that the car will be charged once get home:

$$
E=T * U * K=1.15 \mathrm{kWh}
$$

Where;

$E$ Is the total energy used,

$T$ Is the duration of journey (10 minutes), $U$ Is the average driving speed(30mph), and

$K$ Is the energy consumption coefficient $(0.23 \mathrm{kWh} / \mathrm{mile})$.

Calculation show that according to these data, in 10 minutes' drive, the car will consume $1.15 \mathrm{kWh}$ and in the case of electric vehicle where battery size is $5 \mathrm{kWh}$ with $60 \%$ of that capacity available for driving, it will not fully discharge the battery till the end of this drive [9].

$$
T=E / P * N
$$

Where;

$P$ Is charging level $(2.99 \mathrm{~kW}$ based on specification of the charger 13Ams at 230 Volts) and $N$ Charging efficiency assumed to be $90 \%$.

It is essential to determine the total power of the car battery due to its utmost requirement. The charging rate therefore, is determined in the rush hour that is closest to returning to house time. According to the transportation needs, various ways of recharge were evaluated keeping in mind the demand of charging needs pertinent to given restrictions. The most important is the Slow and Normal Rate of Charging, applicable for the distribution of LV to provide a number of points for charging cars which is provided in driving lots. In addition, the fast charging, this is designed to provide various charging points. These points directly supplied from MV. These points provides recharging at higher rate in the rush time.

\section{CONCLUSIONS AND DISCUSSION}

The electricity demand is increasing with time, comparable with increasing number of households in the UK due population growth, household's appliances ownership and expected market share of PHEV in the UK. Energy consumption depends on conventional trends but today scientists have a tendency to to improve different strategies and move towards renewable energy sources particularly PV system to meet the domestic demand.

The main question is how can compacts with the impacts of emerging electric vehicle alongside with supply the household's electricity demand for domestic appliances assist UK domestic need. Overall, daily demand of domestic electricity is increase when appliances are mostly used and when energy peak demand occur. In this paper, key approach highlighted regarding managing the domestic consumption through managing the houses loads by understanding the customer behaviors and classifying the time where customer is frequently active as well as inactive. So, it is about time habit and behavior of daily usage of every individual customer. Therefore, there is a essential need to explore the individual customer and profile the individual demand pre considering connecting PHEV to the domestic grid in order to re-manage the priorities of supplying and usage.

In the reviewed investigation, data about PHEVs electricity demand is strongly recommended to be observed individually. Domestic charging load which is related with utility that provides the supply to these charging points have to adopt some new solution for time charging to decrease peak load. New solution for increasing domestic demands will help to change future and relief our environment. So far, lack of domestic information on individual demand is keeping us away behind schedule. For reducing or managing daily demand whereas increased prices is going for electricity by Knowing those facts, new ways can be found and use to manage PHEV charging time on the most suitable and cheaper way. Another recommended solution is to widely adopt domestic renewable energy sources and politically funding deployment of using domestic renewable energy sources, which is considered expensive option due to the capital cost of such systems.

\section{REFERENCES}

[1] Department of transport, Low carbon transport: A greener future, department of transport, a carbon reduction strategy July 2009.

[2] S. Huang and D. Infield, "The impact of domestic plug-in hybrid electric vehicles on power distribution system loads," in Power System Technology (POWERCON), 2010 International Conference on, 2010, pp. 1-7.

[3] M. Kintner-Meyer, K. Schneider and R. Pratt, "Impacts assessment of plug-in hybrid vehicles on electric utilities and regional US power grids, Part 1: Technical analysis," Pacific Northwest National Laboratory (a), pp. 1-20, 2007.

[4] K. Clement-Nyns, E. Haesen and J. Driesen, "The impact of charging plug-in hybrid electric vehicles on a residential distribution grid," Power Systems, IEEE Transactions on, vol. 25, pp. 371-380, 2010.

[5] M. G. Pollitt, "UK renewable energy policy since privatisation," in Harnessing Renewable Energy in Electric Power Systems: Theory, Practice, Policy, RFF Press, 2010.

[6] S. Huang and D. Infield, "The potential of domestic electric vehicles to contribute to power system operation through vehicle to grid technology," in Universities Power Engineering Conference (UPEC), 2009 Proceedings of the 44th International, 2009, pp. 1-5.

[7] G. Wood and M. Newborough, "Dynamic energy-consumption indicators for domestic appliances: environment, behaviour and design," Energy Build., vol. 35, pp. 821-841, 2003.

[8] The UK electricity associate load research team., UK housing energy fact -file 2012 . 
[9] Sheboniea, M., Darwish, M., Janbey,A., "Review of UK Domestic Electricity Consumption and Potential Trends in Using Renewable Energy Sources and Plug-in Hybrid Electrical Vehicles," International Review of Electrical Engineering (IREE), vol. 10, 2015.

[10] BRE on behalf of the Department of Energy and Climate Change, "Energy follow-up survey 2011, Report9, domestic appliances, cooking and cooling equipment, December 2013 .

[11] I. C. Jason Palmer, "United kingdom housing energy fact file 2013, department of energy \& climate change.

[12] DECC, Smart metering implementation programme government response to the consultation on the consumer engagement strategy.

[13] V. Hamidi, F. Li and F. Robinson, "Demand response in the UK's domestic sector," Electr. Power Syst. Res., vol. 79, pp. 1722-1726, 2009.

[14] F. W. Geels, "A socio-technical analysis of low-carbon transitions: introducing the multi-level perspective into transport studies," J. Transp Geogr., vol. 24, pp. 471-482, 2012.
[15] S. Abras, S. Ploix, S. Pesty and M. Jacomino, "A multi-agent home automation system for power management," in Informatics in Control Automation and Robotics, Springer, 2008, pp. 59-68.

[16] A. Rautiainen, S. Repo, P. Järventausta, A. Mutanen, K. Vuorilehto and K. Jalkanen, "Statistical charging load modelling of PHEVs in electricity distribution networks using national travel survey data," Smart Grid, IEEE Transactions on, vol. 3, pp. 1650-1659, 2012.

[17] Siti, M., Tiako,R, "Optimal Energy Control of a Grid-Connected Solar Wind-Based Electric Power Plant Applying Time-of-Use Tariffs," International Review of Electrical Engineering (IREE), vol. 10, 2015.

[18] J. E. Fischer, S. D. Ramchurn, M. Osborne, O. Parson, T. D. Huynh, M. Alam, N. Pantidi, S. Moran, K. Bachour and S. Reece, "Recommending energy tariffs and load shifting based on smart household usage profiling," in Proceedings of the 2013 International Conference on Intelligent User Interfaces, 2013, pp. 383-394. 